\title{
AS LIÇÕES QUE O CICLO NUCLEAR DE CAETITÉ/BA TEM A OFERECER A ANGRA 3: VIOLAÇÕES AO DIREITO HUMANO AO MEIO AMBIENTE.
}

\author{
Camila Marques Gilberto ${ }^{1}$ \\ Flávia de Oliveira Santos do Nascimento ${ }^{2}$
}

\section{RESUMO}

$\mathrm{O}$ presente artigo analisa o direito humano ao meio ambiente à luz de princípios administrativos ambientais aplicados ao ciclo nuclear brasileiro. A notícia da retomada das obras de Angra 3 reacende o debate sobre os riscos da geração de energia nuclear. O processo de geração envolve a extração e enriquecimento de minério de urânio, atividade desenvolvida no município de Caetité/BA. Tais atividades demandam fiscalização efetiva das autoridades públicas. Assim, convém analisar o histórico enfrentado por este município numa luta desigual. Para tanto, utiliza-se de metodologia de revisão bibliográfica, especialmente em estudos e relatórios oficiais relevantes sobre o tema.

Palavras-chaves: Direito Humano ao Meio Ambiente; Princípios Administrativos; Energia Nuclear; Dano Ambiental; Direito Ambiental.

\section{THE LESSONS THAT THE NUCLEAR CYCLE OF CAETITÉ/BA HAS TO OFFER ANGRA 3: VIOLATIONS TO THE HUMAN RIGHT TO THE ENVIRONMENT.}

\begin{abstract}
This article analyzes the human right to the environment in light of environmental administrative principles applied to the Brazilian nuclear cycle. The news of the resumption of works on Angra 3 rekindles the debate on the risks of generating nuclear energy. The generation process involves the extraction and enrichment of uranium ore, an activity developed in the municipality of Caetité/BA. Such activities require effective inspection by public authorities. Thus, it is convenient to analyze the history faced by this municipality in an unequal struggle. For this purpose, a literature review methodology is used, especially in relevant studies and official reports on the subject.
\end{abstract}

Keywords: Environmental Human Right; Administrative Principles; Nuclear energy; Environmental Damage; Environmental Right.

\section{INTRODUÇÃO}

\footnotetext{
${ }^{1}$ Doutoranda em Direito Ambiental Internacional pela Universidade Católica de Santos. Mestre em Direito Internacional. Membro do grupo de pesquisa "Direitos Humanos e Vulnerabilidades". Professora da Universidade Católica de Santos. Advogada.

${ }^{2}$ Doutoranda em Direito Ambiental Internacional pela Universidade Católica de Santos. Mestre em Direito Ambiental. Membro do grupo de pesquisa "Regimes e Tutelas Constitucionais, Ambientais e Internacionais". Professora da Universidade Católica de Santos. Advogada.
} 
O ciclo nuclear brasileiro sempre foi objeto de amplos debates. Enquanto especialistas destacam o alto custo para produção de energia nestes moldes em comparação à entrega energética para o país, o país anuncia a retomada das obras de Angra $3^{3}$.

Com previsão de início para junho de 2021 e conclusão até 2026, o governo brasileiro reacende discussões em torno da suposta necessidade de expansão de geração nuclear no país. Ainda que se argumente que a fonte de energia nuclear é limpa e pode ser implantada próxima a centros de consumo, os danos colaterais de sua geração deflagram, na maior parte das vezes, violações de direitos humanos; notadamente ao direito humano ao meio ambiente, objeto de análise do presente artigo.

A fonte primordial de incentivo à produção deste tipo de energia está relacionada ao fato de o país possuir a sexta maior reserva geológica de concentrado de urânio do mundo. A abundância da matéria prima essencial ao desenvolvimento da energia nuclear é um propulsor, há algumas décadas, da construção e operação de usinas nucleares no Brasil.

A história recente, nacional e internacional, dá conta dos inúmeros revezes que esta cadeia produtiva pode gerar à população. As mais conhecidas envolvem os riscos de acidentes e, no presente caso, objeto deste estudo, externalidades negativas experimentadas pela população que resido no entorno destas instalações e daquelas próximas às minas de extração de urânio.

Neste sentido, o presente artigo propõe uma reflexão acerca destas externalidades negativas, dos danos ambientais e, principalmente, violações de direitos humanos. Para isso, será trazido à baila o exemplo de violação ao direito humano ao meio ambiente no ciclo nuclear de Caetité, município localizado no estado da Bahia e sede de umas das maiores minas de extração de urânio do país.

Os danos ao meio ambiente e as violações de direitos humanos sofridas por esta população compõe a narrativa de uma história cujo final é conhecido: vozes silenciadas e gerações sofrendo com os efeitos nefastos provocados pelos recorrentes acidentes ao longo do ciclo nuclear brasileiro.

A metodologia empregada na construção do presente artigo foi desenvolvida utilizando-se o método de abordagem hipotético-dedutivo, valendo-se de técnica de pesquisa

\footnotetext{
${ }^{3}$ No dia 13.05.2021 foi anunciada a retomada das obras de Angra 3. "Governo vai retomar obras de Angra 3 e investimentos totais podem chegar a R\$ 15 bi”. Jornal o Estado de S. Paulo. Matéria veiculada em 14.05.2021. Disponível em: <https://economia.estadao.com.br/noticias/geral,governo-vai-retomar-obras-de-angra-3-einvestimentos-totais-podem-chegar-a-r-15-bi,70003714630>. Acesso em 14.05.2021.
} 
bibliográfica lastreada em doutrinas, publicações avulsas, artigos, teses e relatórios oficiais. A pesquisa legislativa refere-se a fontes nacionais e internacionais, tais como, tratados, convenções e outros.

\section{AS VIOLAÇÕES DE DIREITOS NO CICLO NUCLEAR DE CAETITÉ/BA}

O desenvolvimento de programas nucleares para fins energéticos é objeto de diversas críticas ao redor do mundo. O Greenpeace, por exemplo, é notoriamente contrário a ciclos nucleares para esta finalidade. Isto porque, o custo energético do ciclo de produção resulta numa margem mínima de benefício frente aos riscos inerentes à atividade (GREENPEACE, 2008). Ademais, os habitantes de cidades no entorno destas instalações são, reiteradamente, vítimas de inúmeras violações de direitos humanos.

O Brasil, entretanto, não atentou a estes alertas. Criado durante o regime militar em 1965, o programa nuclear brasileiro manteve-se estanque até meados de 2007 quando, sob o pretexto de desenvolver fontes menos poluentes de energia, os investimentos outrora realizados foram retomados para a construção da usina de Angra 3 e outras cinco usinas nucleares em outros estados no país (GREENPEACE, 2008).

A retomada das obras de Angra 3 é anunciada há anos. Paralisadas desde 2015, em virtude dos escândalos da Lava Jato, as obras serão reiniciadas em $2022^{4}$ com previsão de conclusão em 2026. Neste período o país viverá a tensão dos riscos inerentes à esta atividade, e os olhares serão voltados a todas as etapas do processo de produção e, especialmente, às populações que vivem próximas a este processo.

O interesse brasileiro no ciclo nuclear é compreensível. O país possui a $6^{\mathrm{a}}$ maior reserva geológica de concentrado de urânio do mundo (GREENPEACE, 2008), o que justifica analisar o que foi feito desta reserva no passado e, talvez, retirar algumas lições para o futuro.

\footnotetext{
${ }^{4}$ Muito embora o anúncio de retomada das obras em maio tenha apresentado cronograma de início para o final do primeiro semestre, houve o adiamento dos trabalhos para 2022. Disponível em: <https://www.gov.br/cnen/ptbr/assunto/ultimas-noticias/com-proximidade-da-retomada-de-obras-de-angra-3-equipe-da-cnen-visita-centralnuclear-para-planejar-acoes-de-licenciamento-e-controle>. Acesso em 28.09.2021.
} 
A cidade de Caetité/BA, com seus 51 mil habitantes ${ }^{5}$, abriga uma das minas de concentrado de urânio. O município está localizado a 750 quilômetros da capital Salvador e passou a ser conhecido por dois motivos: sediar a única mina de extração de urânio do país e pela contaminação de suas águas (GREENPEACE, 2008).

A 'Unidade de Concentrado de Urânio das Indústrias Nucleares do Brasil' (URAINB) funciona no município de Caetité, desde o início de 2000. Os trabalhos da URA-INB consistem na atividade de mineração e transformação do urânio mineral em licor de urânio e este em concentrado de urânio, yellow cake, pó de cor amarelada com $70 \%$ de teor de urânio (PLATAFORMA DHESCA, 2011). A atividade da mina de urânio é a primeira etapa necessária ao ciclo da energia nuclear no país, já que o yellow cake é o principal componente do combustível nuclear.

As Indústrias Nucleares do Brasil ${ }^{6}$ (INB), responsável pela URA-INB, atuam na cadeia produtiva do urânio desde a mineração até a fabricação do combustível nuclear atividades que são monopólio da União, nos termos do artigo 21, inciso XXIII da Constituição Federal de 1988.

De 2000 até 2015 foram produzidas 3.750 toneladas de concentrado de urânio. As atividades foram paralisadas de 2015 a 2020 por conta da exaustão dos recursos passíveis de lavra a céu aberto da Mina Cachoeira. Em dezembro de 2020 as atividades da URA-INB foram retomadas com extração a partir da Mina do Engenho ${ }^{7}$.

Entretanto, em relatório produzido em 2008, o Greenpeace enfatizava os riscos da liberação do urânio no meio ambiente que passa a compor a cadeia alimentar humana, seja pela água ou, até mesmo, leite e vegetais. A ingestão contínua do urânio, ainda que em pequenas quantidades, tem o potencial de causar inúmeros danos à saúde, como cânceres e problemas renais (GREENPEACE, 2008).

Os impactos sociais e ambientais gerados URA-INB ao longo da primeira lavra da Mina Cachoeira comprovam o que a literatura ambiental sempre advertiu: a energia nuclear é perigosa e poluente desde a sua origem.

\footnotetext{
5 Evolução populacional, IBGE. Disponível em: 〈https://cidades.ibge.gov.br/brasil/ba/caetite/panorama〉. Acesso em 14.05.2021.

${ }^{6}$ A INB foi criada em 1988 sucedendo à Nuclebrás. Em 1994 incorporou as atividades de atribuições de suas controladas - Nuclebrás Enriquecimento Isotópico S.A. (Nuclei); Urânio do Brasil S.A. e Nuclemon Mínero Química Ltda. Página institucional das Indústrias Nucleares do Brasil. Disponível em: <http://www.inb.gov.br/pt-br/WebForms/interna.aspx?secao_id=4>. Acesso em 14.05.2021.

${ }^{7}$ Disponível em: <https://www.inb.gov.br/Detalhe/Conteudo/inb-caetite-volta-a-produzir-uranio-para-geracaode-energia-no-brasil/Origem/395>. Acesso em 14.05.2021.
} 
Segundo o Greenpeace,

\begin{abstract}
A técnica de extração do urânio depende do minério a que se encontra associado para definir o processo com a melhor relação custo-benefício. $\mathrm{O}$ minério de urânio é normalmente moído para facilitar o 'ataque' por agentes químicos. O urânio é então lixiviado com ácido para ser separado do minério. A solução obtida, denominada licor de urânio, é depois purificada por métodos químicos. O produto final desse beneficiamento é um concentrado de urânio (U3O8), um pó de cor amarela, conhecido por yellow cake, que contém aproximadamente $70 \%$ do urânio do minério. Hoje, no Brasil, essas etapas são realizadas unicamente na unidade da INB em Caetité (BA). De acordo com estudos de viabilidade, o teor e as reservas da mina na Bahia seriam suficientes para o suprimento de Angra 1, 2 e 3 por um período estimado em cem anos. O yellow cake segue em caminhões para o porto de Salvador, de onde é enviado ao Canadá para a etapa de conversão para o gás UF6. Em seguida, o material é encaminhado ao consórcio Urenco, na Holanda, para o enriquecimento isotópico, cujo objetivo é aumentar a concentração de urânio- 235 presente a $0,7 \%$ no estado natural para $2 \%$ a $5 \%$, servindo então como combustível nuclear. Só então o material retorna ao Brasil, pelo Rio de Janeiro, e segue para a Fábrica de Combustível Nuclear (FCN) da INB localizada em Resende, no Rio de Janeiro. Na FCN, o gás UF6 é reconvertido ao estado sólido (dióxido de urânio) e transformado em pastilhas. As pastilhas de dióxido de urânio por fim são montadas em varetas metálicas especiais. O conjunto das varetas é a fonte de calor da geração termonuclear nas usinas de Angra dos Reis através da fissão de núcleos de átomos de urânio (2008, p. 07).
\end{abstract}

$\mathrm{Na}$ primeira década de funcionamento da URA-INB, inúmeros acidentes foram documentados. Em 2000, pouco após sua instalação, reportou-se o vazamento de 5 milhões de litros de licor de urânio das bacias de sedimentação para o meio ambiente, fato este denunciado apenas 6 meses após a ocorrência com aplicação de multa máxima à INB pelo Centro de Recursos Ambientais. (PLATAFORMA DHESCA, 2011).

Este episódio resultou na instauração de uma Ação Civil Pública pelo Ministério Público Estadual, o qual determinou a suspensão da licença de instalação e das atividades da INB, paralisadas durante nove meses.

Em abril de 2002, foi denunciado vazamento na 'área 170' com possível contaminação do lençol freático. O vazamento foi inicialmente omitido da população e autoridades. Após a denúncia, o Ministério Público Federal acionou o Ministério Público Estadual para que fossem tomadas providências (PLATAFORMA DHESCA, 2011).

No período de janeiro a junho de 2004, a bacia de barramento de 'finos' teve transbordos diversas vezes, liberando no meio ambiente líquido com concentração de urânio- 
238, tório-232 e rádio-226. O incidente levou à mortandade de peixes nas lagoas do entorno da mina (PLATAFORMA DHESCA, 2011).

Em virtude do acidente, a INB foi novamente autuada e multada pelo IBAMA em razão do descumprimento de condicionantes ${ }^{8}$ estabelecidas na Licença de Operação emitida pelo órgão em outubro de 2002. Isto resultou na instalação de mais um inquérito civil pelo Ministério Público Estadual.

No primeiro semestre de 2006, as atividades da URA-INB foram paralisadas por dois meses em virtude de mais um acidente: o rompimento de uma das mantas da bacia de licor de urânio (PLATAFORMA DHESCA, 2011).

Em 2010, o rompimento de tubulação da URA-INB levou 900 litros de licor de urânio ao solo, na área de extração e beneficiamento do minério. Foram identificados pontos de contaminação por radioatividade nos poços localizados no entorno da mina e utilizados para abastecimento de dezenas de famílias (PLATAFORMA DHESCA, 2011).

Mais da metade da população de Caetité/BA vive na zona rural e extrai da terra sua fonte de subsistência, utilizando água de poços artesianos e riachos próximos à mina de urânio. Neste sentido, dezenas de milhares de pessoas estão continuamente expostas aos efeitos gerados pela contaminação de urânio, que transcende gerações.

Considerando a extensão das violações de direitos humanos geradas pela atividade da URA-INB ao longo do seu primeiro ciclo de operações de 2000 a 2015 na Mina Cachoeira, importante refletir o que este histórico representa para a proteção ao direito humano ambiental e efetivação dos princípios inerentes ao Direito Ambiental, para que se possa avaliar em que medida o país está preparado para lidar com a responsabilidade de manter o ciclo nuclear em ação.

2. O DIREITO HUMANO AMBIENTAL E OS PRINCÍPIOS DO DIREITO AMBIENTAL: FERRAMENTAS NA GUERRA DO CICLO NUCLEAR DE CAETITÉ/BA.

\footnotetext{
${ }^{8}$ Após o acidente de 2000, o IBAMA emitiu nova licença de Operação à INB em 2002, estabelecendo 13 condicionantes a serem cumpridas pela empresa, entre elas: o monitoramento da saúde dos trabalhadores e da população e falta de exames hidrogeológicos, relatórios periódicos com acompanhamento de endemias, epidemias e aparecimento de novas doenças e patologias relacionadas aos danos genéticos pré-existentes e neoexistentes. (PLATAFORMA DHESCA, 2011, p. 22).
} 
Em 1948, a Declaração Universal de Direitos Humanos (Declaração Universal) trouxe a tônica do que viria a ser um intrincado acabouço normativo para a proteção ao direito humano ambiental. Entretanto, foi apenas com a Declaração de Estocolmo de $1972^{9}$ (Declaração de Estocolmo) que este sistema passou a se desenvolver concretamente.

A Declaração de Estocolmo inaugurou a arquitetura de um sistema de proteção ao direito ambiental internacional. $\mathrm{O}$ documento produzido, expande em proteção e alcance as condutas e direitos previstos na Declaração Universal. Os 26 princípios trazidos na Declaração de Estocolmo definem standards, condutas e direitos essenciais a proteção deste bem comum.

Segundo Silva (2010), a Declaração de 1972 serviu para abrir o caminho para que ordenamentos jurídicos supervenientes abarcassem, em suas Constituições, o meio ambiente ecologicamente equilibrado como um direito fundamental entre os direitos sociais do homem, com sua característica de direitos a serem realizados e direitos a não serem perturbados.

Alocado à categoria de direito humano de terceira dimensão, o meio ambiente traduz uma das características mais importantes dos direitos humanos: a interdependência. Isto porque, demanda ações positivas do Estado - afetas a segunda dimensão de direitos humanos e, ao mesmo tempo, demanda ações negativas, ou seja, abstencionistas para que se evite uma violação de direitos - afetos a primeira dimensão de direitos humanos (PIOVESAN, 2019).

Esta característica difusa e coletiva resulta na categorização de direito de terceira dimensão. Bonavides (1993) destaca a importância desta dimensão:

[...] Dotados de altíssimo teor de humanismo e universalidade, os direitos da terceira geração tendem a cristalizar-se neste fim de século enquanto direito que não se destinam especificamente à proteção dos interesses de um indivíduo, de um grupo ou de um determinado Estado. Têm primeiro por destinatário o gênero humano mesmo, num momento expressivo de sua afirmação como valor supremo em termos de existencialidade concreta. Os publicistas e juristas já os enumeram com familiaridade, assinalando-lhes o caráter fascinante de coroamento de uma evolução de trezentos anos na esteira da concretização dos direitos fundamentais. Emergiram eles da reflexão sobre temas referentes ao desenvolvimento, à paz, ao meio ambiente, à comunicação e ao patrimônio comum da humanidade. (1993, p. 481)

\footnotetext{
${ }^{9}$ Declaração do Meio Ambiente, adotada pela Conferência das Nações Unidas em junho de 1972.
} 
Evidentemente, o objeto tutelado não se limita apenas ao meio ambiente natural (entendido como o patrimônio físico ou natural: solo, água, ar, flora e fauna), mas um conjunto que engloba, também, o meio ambiente artificial (conjunto de edificações e equipamentos públicos) e o meio ambiente cultural (patrimônio histórico, artístico, paisagístico, turístico, arqueológico) que possibilite o desenvolvimento equilibrado da vida em todas as suas formas (SILVA, 2010).

Após duas décadas, os princípios da Declaração de Estocolmo foram reafirmados e expandidos de modo que, disposições sobre desenvolvimento sustentável e meio ambiente, fossem acrescentadas durante a Conferência das Nações Unidas sobre Meio Ambiente, realizada em junho de 1992 no Rio de Janeiro - Rio/92. (SILVA, 2010).

O ordenamento jurídico brasileiro assimilou lentamente, por sua vez, os princípios aprovados pela Declaração de Estocolmo, iniciando seu próprio processo de proteção ao meio ambiente. O grande destaque desse movimento foi a Lei Federal $n^{\circ} 6.938 / 81$, que estabeleceu a Política Nacional para o Meio Ambiente (SILVA, 2010) cujo objetivo foi criar instrumentos de defesa, bem como a atribuição de responsabilidade pela prática de danos ambientais (GRANZIERA, 2009).

Com a Constituição Federal de 1988, o direito ao meio ambiente ecologicamente equilibrado foi alçado à categoria de direito fundamental no artigo $225^{10}$, destacado das garantias previstas no artigo $5^{\circ}$ (DERANI, 2008). Somente mediante a plena realização deste amplo e complexo direito humano, fruto de evolução histórica, será garantida uma vida digna e sadia a todos (GRANZIERA, 2009).

Analisando a construção do artigo 225 da Constituição Federal, Silva identifica, claramente, a influência das Declarações de Estocolmo e do Rio de Janeiro. O artigo reflete, direta ou indiretamente, ao longo de seus parágrafos e incisos, os princípios daqueles instrumentos (SILVA, 2010).

A seguir, serão analisados alguns que têm influência direta na análise do caso de Caetité/BA e servirão de base para futuras ações fiscalizatórias das autoridades públicas.

\footnotetext{
${ }^{10}$ Constituição Federal, Art. 225 - Todos têm direito ao meio ambiente ecologicamente equilibrado, bem de uso comum do povo e essencial à sadia qualidade de vida, impondo-se ao Poder Público e à coletividade o dever de defendê-lo e preservá-lo para as presentes e futuras gerações.
} 
Os Princípios n. $1^{11}$ das Declarações de Estocolmo e do Rio de Janeiro tratam do direito à sadia qualidade de vida, traduzindo a visão antropocêntrica do direito ambiental e encontram correspondência no caput do artigo 225 e em seu $\S 1^{\circ}$, V.

A construção normativa do artigo ultrapassa a garantia do direito à vida para exigir que esta seja usufruída com qualidade, em observância ao princípio norteador do texto constitucional: o respeito à dignidade da pessoa humana (DERANI, 2008). Não é admissível, neste sentido, que a intervenção humana ao meio ambiente importe em danos a toda uma coletividade, como ocorreu na cidade de Caetité/BA.

Os Princípios da Precaução e Prevenção $\left(225, \S 1^{\circ}\right.$, incisos, IV, V, VII e $\S 6^{\circ}$ da Constituição Federal de 1988) trazem um dos comandos mais importantes a ser observado pelo Estado em toda conduta humana junto ao meio ambiente. Sua origem data, entretanto, é anterior à promulgação da Constituição de 1988, sendo previstos pela Lei de Política Nacional do Meio Ambiente (Lei Federal 6.938/81).

Como esclarece Machado (2010), enquanto o Princípio da Prevenção busca minimizar os riscos que são conhecidos pela conduta humana no meio; o Princípio da Precaução regula um tipo de conduta que reflete o perigo in abstrato, uma vez que não existe conhecimento disponível sobre o impacto ao meio ambiente gerado pela intervenção humana.

Martins Júnior (2014) anota que, pelo Princípio da Prevenção os riscos concretos impõem providências a fim de evitá-los, já pelo Princípio da Precaução, são os riscos abstratos que atribuem necessidade de antecipação. Ambos demandam maior intervenção do Estado na restrição de determinadas atividades econômicas através da análise de riscos e traduzem a ideia de que aquele que cria o perigo por ele será responsável.

A análise de risco que justifica a aplicação dos Princípios da Precaução e da Prevenção está inserida na metodologia utilizada para elaboração do Estudo de Impacto Ambiental e Relatório de Impacto Ambiental - EIA-RIMA (MARTINS JUNIOR, 2014). A conclusão deste estudo determinará a aprovação/reprovação de um empreendimento.

\footnotetext{
${ }^{11}$ Princípio n.1 da Declaração de Estocolmo: O homem tem o direito fundamental à liberdade, à igualdade e ao desfrute de condições de vida adequadas em um meio ambiente de qualidade tal que lhe permita levar uma vida digna e gozar de bem-estar, tendo a solene obrigação de proteger e melhorar o meio ambiente para as gerações presentes e futuras. A este respeito, as políticas que promovem ou perpetuam o apartheid, a segregação racial, a discriminação, a opressão colonial e outras formas de opressão e de dominação estrangeira são condenadas e devem ser eliminadas.

Princípio n.1 da Declaração do Rio de Janeiro: Os seres humanos estão no centro das preocupações com o desenvolvimento sustentável. Têm direito a uma vida saudável e produtiva, em harmonia com a natureza.
} 
Interessante notar que, o processo de licenciamento nuclear e ambiental da Unidade de Concentrado de Urânio apresentou falhas desde o início. O EIA/Rima que antecedeu a instalação do empreendimento já apontava riscos de contaminação da água, tendo sido ignorado pelos órgãos de licenciamento e fiscalização, IBAMA e a Comissão Nacional de Energia Nuclear $(\mathrm{CNEN})^{12}$.

O panorama descrito não impediu, contrariando pareceres técnicos produzidos pelo próprio IBAMA, que a Licença de Operação da mina fosse renovada duas vezes: em 2002 pelo período de 4 anos - e em janeiro de 2007 - por mais 6 anos. (PLATAFORMA DHESCA, 2011).

A conduta da Administração Pública neste caso, viola, diretamente, o cerne do que preconiza o princípio da precaução. Cirurgicamente, aponta Martins Júnior (2014),

[...] a Administração Pública deve se orientar pela precaução, condicionando sua natureza ou em seus efeitos com a imposição de medidas mais severas ou a proibição da atividade até a obtenção da certeza necessária - e não pela procrastinação de providências que previnam a lesão ao bem jurídico tutelado. Para a efetivação de direitos como a vida, indenidade, sossego, etc. não custa obviar que reparar prejuízos advindos de atividade perigosa recuperação essa que pode ser irreparável ou difícil - é afinada ao ordenamento jurídico a atuação antecipatória a riscos de danos. (p. 219).

Machado (2010), por sua vez, é enfático quanto à análise destes princípios frente ao risco de dano nuclear tendo em vista que o Poder Público, em qualquer de suas esferas, está obrigado a respeitar o direito à vida dos cidadãos; não sendo admissível que adote conduta homicida e/ou genocida e, tampouco, ecocida, quando se fala em acidentes no processo de geração de energia nuclear.

Os Princípios do Usuário-Pagador/Poluidor-Pagador e o Princípio da Reparação (Art. $225, \S 2^{\circ}$ e $\$ 3^{\circ}$ da Lei Maior) trazem comando coercitivo e sancionador a ser aplicado àqueles que, mediante exploração ou utilização indevida dos bens, recursos e serviços ambientais, causem danos ao meio ambiente.

\footnotetext{
${ }^{12}$ Segundo relatório do Greenpeace: "Vale notar que o RIMA da URA Caetité (INB, 1997) já indicava alterações nos indicadores de saúde na região, ressaltando que 'as neoplasias e os indicadores de possível dano genotóxico foram os mais investigados'. Segundo o documento, 'foi constatado um risco diferenciado de morrer por algumas neoplasias e de ocorrência de danos genotóxicos na área de influência do empreendimento, ao ser comparada com outros municípios do semi-árido baiano onde inexistem ocorrências de jazidas de urânio"”. GREENPEACE, 2008, p. 5 e 7.
} 
Com efeito, isto não confere carta branca ao poluidor para que assim aja, como pondera Martins Júnior (2014),

[...] Curial obtemperar que o princípio do poluidor-pagador não significa pagar para poluir nem se esvai no princípio da responsabilidade civil, mas, isto sim, que o poluidor deve arcar com os custos relativos às medidas de prevenção, e não transferi-los ao poder público, embora sejam aproveitados no custo final de sua atividade e repercutam no preço de bens e serviços. Também não se confunde com o princípio de usuário-pagador, que consiste no pagamento pelo aprovei- tamento de recursos ambientais públicos e não concretiza sanção por ato ilícito (p. 215).

Ou seja, a estes é imposto o dever de pagar pelo acesso ao meio, racionalizando-se, assim, o uso ou o impacto gerado pela internalização das externalidades negativas (DERANI, 2008) e o dever de reparar os danos causados. A reparação do bem tutelado ao estado anterior sempre terá preferência à indenização. Entretanto, quando não for possível a reparação, haverá sua conversão em indenização e/ou medidas de compensação ambiental.

No processo de geração de energia nuclear é razoável dizer que a reparação do bem é praticamente impossível. Entre os maiores acidentes ocorridos no último século, Chernobyl (1986), Goiânia e o Césio-137 (1987), Fukushima (2011), são prova da impossibilidade de reparação. Neste sentido, a via indenizatória é utilizada para mitigar os danos causados.

O Princípio n. $10^{13}$, Princípio da Informação e Participação, adotado na Declaração do Rio, está traduzido no caput do artigo 225 e em seu parágrafo $\S 1^{\circ}$, inciso VI.

O comando enunciado pelo caput do artigo 225, por sua vez, só pode ser cumprido mediante acesso à informação - incumbência do Poder Público - que possa dar azo à efetiva participação popular. Pelo Princípio da Transparência, o administrado deixa de ser espectador passivo e se torna agente colaborador na tomada de decisões administrativas (MARTINS JUNIOR, 2010).

Para Derani (2008), o artigo em comento oferece uma dimensão dupla de direitos fundamentais, uma de ordem subjetiva e outra objetiva:

\footnotetext{
13 Princípio 10, Declaração do Rio: A melhor maneira de tratar as questões ambientais é assegurar a participação, no nível apropriado, de todos os cidadãos interessados. No nível nacional, cada indivíduo deve ter acesso adequado a informações relativas ao meio ambiente de que disponham as autoridades públicas, inclusive informações sobre materiais e atividade perigosas em suas comunidades, bem como a oportunidade de participar em processos de tomada de decisões. Os Estados devem facilitar e estimular a conscientização e a participação pública, colocando a informação à disposição de todos. Deve ser propiciado acesso efetivo a mecanismos judiciais e administrativos, inclusive no que diz respeito a compensação e reparação de danos.
} 
[...] Por um lado, o poder do sujeito afetado no seu direito à sadia qualidade de vida de voltar-se contra o Poder Público ou contra o poluidor para fazer respeitar esse direito, por exemplo através da atuação em juízo. Uma outra faculdade colocada à disposição do cidadão é a de participação nas decisões administrativas, seja em discussões durante audiências públicas, seja por outros caminhos, como fazendo valer seu direito de representação e o de informação sobre os atos administrativos. Por outro lado, este direito se desdobra no dever do Poder Público, no âmbito de sua competência legislativa ou executiva, de atuar com o objetivo de criar condições para a sua efetivação. (p. 217)

O caso de Caetité/BA é emblemático neste sentido. A população não foi comunicada, prontamente, sobre os acidentes ocorridos ao longo dos anos e sobre a situação da água utilizada para consumo. Tampouco houve mapeamento pelos órgãos competentes para justificar o crescente índice de neoplasias e óbitos por câncer. (PLATAFORMA DHESCA, 2011).

A ausência de divulgação sobre os riscos a que se sujeitou a população da cidade viola este princípio. A população sofreu os efeitos da desinformação e foi impedida de tutelar não só o bem coletivo como o individual. Como os efeitos da contaminação por urânio só são observados a longo prazo, as vítimas não têm condições de obter reparações do governo condizentes com as violações sofridas.

Contrariamente, não há que falar sobre a aplicação de sigilo de atividades da CNEN, prevista no artigo $27^{14}$ da Lei Federal n. 4.118/62. A discricionariedade prevista neste artigo não autoriza a CNEN a se furtar a prestar informações sobre as atividades desenvolvidas na URA-INB. Isto porque, manter sigilo sobre informações é conduta excepcional na Administração Pública, que tem o dever de prestar informações de interesse público (MACHADO, 2010).

Importante lembrar que o fundamento da tutela ambiental tem como pressuposto (explícito ou implícito) a saúde humana, uma vez que era este o bem tutelado antes da constitucionalização do meio ambiente (MILARÉ, 2005). Assim, os danos provocados ao meio ambiente pela atuação da mina de urânio impactam direta e indissociavelmente na saúde da população do entorno.

\footnotetext{
${ }^{14}$ Art. 27. O caráter sigiloso das atividades da CNEN será estabelecido pela Comissão, quando julgar necessário, caso não tenha sido determinado previamente por órgãos com autoridade para fazê-lo.

Parágrafo único. A desclassificação do caráter sigiloso poderá ser feita pelo órgão que a tiver estabelecido, por sua própria iniciativa ou por solicitação fundamentada pela Comissão.
} 
Do mesmo modo, os habitantes de Caetité/BA sofrem reflexos econômicos pela contínua atuação da URA-INB na medida em que suas propriedades desvalorizaram pela atuação da mina. Percebe-se, assim, que as violações de direitos desbordam o dano ambiental, a despeito de qualquer assunção de responsabilidade pelos agentes causadores do dano.

Não é razoável, no entanto, que diante de tamanho arcabouço normativo presente no ordenamento jurídico brasileiro, as violações a direitos humanos observadas no ciclo nuclear de Caetité/BA não tenham conseguido, em mais de uma década, obter a adequada tutela jurisdicional.

Os mecanismos de defesa do bem ambiental consagrados no ordenamento jurídico brasileiro estão dispostos nos artigos $5^{\circ}$, inciso LXXIII e artigo 129, inciso III. Neste sentido, a propositura de Ações Populares e Ações Civis Públicas correspondem aos instrumentos aptos a tutelar interesses difusos e coletivos.

Ocorre que, no caso de Caetité/BA, as investigações iniciadas pelos órgãos oficiais e as medidas judiciais adotadas não fizeram cessar ou reparar as violações reiteradamente perpetradas e, tampouco, informaram a população diretamente afetada pelas atividades da URA-INB sobre os riscos a que estão expostos.

Inúmeras multas e autuações foram imputadas à INB em razão da exploração da mina $^{15}$. Entretanto, não foram suficientes para sanar, ao longo de mais de 10 anos de operação, as condicionantes estabelecidas pelo IBAMA no que diz respeito, por exemplo, ao monitoramento da saúde dos trabalhadores da mina e da população do entorno, e a falta de transparência de informações sobre acidentes ocorridos, controle da qualidade da água e tantos outros aspectos técnicos (PLATAFORMA DHESCA, 2011).

Não é surpresa, portanto, que tramitem na Justiça Federal de Guanambi diversas Ações Civis Públicas referentes ao funcionamento da mina de urânio. Uma delas, ajuizada em $2009^{16}$ pelo Ministério Público Federal, 9 anos após a ocorrência dos fatos, tinha por objetivo Indenização por Dano Ambiental e Dano Moral coletivo em face da responsabilidade da

\footnotetext{
${ }^{15}$ Autuação de R \$ 300.000,00 em 08/01/2007 pelo não cumprimento de condicionantes, sem prejuízo de duas autuações em 2004 e duas em 2010, uma delas no valor de R \$1.000.000,00 por ter lançado substância oleosa (solvente orgânico com urânio) no meio ambiente. Em 2011, nova autuação e mula no valor de R $\$ 600.000,00$ por descumprimento dos termos da Licença de Operação que não previa realização de atividade de 'retamboramento' de material proveniente de outra instalação nuclear. (PLATAFORMA DHESCA, 2011).

16 Ação civil pública $\mathrm{n}^{\circ}$ 0000761-18.2009.4.01.3309. Réus do processo: União (Ministério Da Ciência E Tecnologia - MCT), Comissão Nacional de Energia Nuclear - CNEN, Indústrias Nucleares do Brasil S/A - INB, Instituto Brasileiro do Meio Ambiente e dos Recursos Naturais Renováveis - IBAMA.
} 
Administração pelo vazamento de $5.000 \mathrm{~m} 3$ de licor de urânio da bacia da mina da INB no município de Caetité.

Após quase uma década, em 2018, a Ação Civil Pública foi julgada improcedente após ter pedido de prova pericial, pendente de análise por quase 10 anos, indeferido em 2017. O Ministério Público Federal apresentou recurso de Apelação que aguarda julgamento desde 2019. O que impressiona, contudo, é o lapso temporal decorrido entre o acidente e a sentença. Não parece admissível que a prestação jurisdicional seja tão lenta tendo em vista da potencialidade do dano ambiental discutido, que transcende gerações.

Outra Ação Civil Púbica, ajuizada em $2010^{17}$, tem como autores Associações populares afetadas pelas atividades da INB na região. Da mesma forma que a ação de 2009, o pedido contempla Indenização por Dano Ambiental em face da responsabilidade da Administração pela ineficácia da Portaria do IBAMA (nº 69/2004) que renovou a Licença de Operação (n²74/2002) da Unidade de Concentrado de Urânio de Caetité.

Do mesmo modo que a ação ${ }^{18}$ retro mencionada, esta não teve desfecho diferente. Julgada improcedente em outubro de 2018, os autos aguardam julgamento de recurso de Apelação perante o Tribunal Federal da $1^{\mathrm{a}}$ Região.

Na sentença proferida na ACP de 2010, o juízo a quo houve por bem rechaçar o pedido de responsabilização do IBAMA frente às licenças de operação emitidas, considerando que a autarquia não se omitiu frente ao seu poder/dever de fiscalização, não sendo ilegais as prorrogações adotadas diante da discricionariedade do ato administrativo.

Com relação à existência de dano ambiental a sentença indica inexistir qualquer dano. Os acidentes registrados, cuja ocorrência não se discute, são caracterizados como intercorrências registradas e noticiadas pelas autoridades, ainda que intempestivamente.

Do mesmo modo, afastou a ocorrência do dano ambiental por entender que este não restou comprovado. Segundo a decisão, ainda que exista temor e risco potencial, não houve comprovação de que o dano ambiental ou mesmo o declínio da saúde da população tenham relação com a atividade da URA-INB. Sendo improcedentes estes pedidos, também não foi acolhido o pedido de condenação em dano moral coletivo.

\footnotetext{
${ }^{17}$ O processo ainda aguarda a citação dos requeridos. Ação civil pública no 4809.20.10.401330-9. Réus do processo: Indústrias Nucleares do Brasil S/A - INB, Instituto Brasileiro do Meio Ambiente e dos Recursos Naturais Renováveis - IBAMA.

18 Por tratar-se de autos físicos que superam 3.000 páginas, não é possível, no momento de elaboração do presente artigo, analisar a fundo, as razões pelas quais, as ações foram julgadas improcedentes.
} 
A sentença dá conta, ainda, de que as multas aplicadas pelo IBAMA estão dentro da sua esfera punitiva-educativa. Como foram aplicadas ao longo da última década, o órgão não teve sua atuação discutida. Os relatórios analisados ao longo da elaboração do presente artigo, indicam que as multas aplicadas à INB não repararam a característica coletiva do direito humano ambiental e dos direitos econômicos e sociais violados. Há que se ressaltar que, a maioria das penalidades ainda está sendo contestada no Judiciário haja vista o poderio econômico ostentado pela INB. Neste sentido, sequer uma recomposição ao status quo foi possível até o presente momento.

O futuro de processos da mesma natureza não é promissor. Nem mesmo eventual condenação nas Ações Civis Públicas ajuizadas. Com certo ceticismo, Machado (2010) conclui que essas medidas acabam por transformar em pecúnia valores sociais que possuem natureza distinta e não encontram qualquer correspondência no mercado.

Com efeito, o ciclo nuclear brasileiro, com a retomada das obras de Angra 3 e pela exploração da Mina do Engenho pela URA-INB em Caetité, devem ser acompanhadas de perto, haja visto o histórico de violações registradas nas últimas décadas.

\section{CONCLUSÃO}

O presente artigo buscou refletir sobre o direito humano ao meio ambiente aliado à aplicação de alguns princípios administrativos ambientais. O ceticismo da reflexão é peculiar quando se noticia a retomada de obras da usina nuclear de Angra 3.

A despeito dos riscos inerentes à geração de energia nuclear, o histórico de fiscalização e reparação nestas atividades não é promissor, à guisa do que enfrenta a população de Caetité/BA.

Além do direito humano universal a um meio ambiente ecologicamente equilibrado, com obrigações de defesa para as presentes e futuras gerações, compete ao poder público a preservação, restauração e educação ambientais, seja por meio de atividades normativas, preventivas, fiscalizatórias e/ou educacionais; sem olvidar, obviamente, do dever de recuperação por parte daquele que degrada o meio ambiente, em observância ao Princípio do Poluidor-Pagador, comandos do artigo 225, da Constituição Federal. 
O exemplo de Caetité/BA e a morosidade com que suas questões foram enfrentadas administrativa e judicialmente dão a tônica do que pode vir a ser a nova era do ciclo nuclear brasileiro: litígios que se desenrolam por décadas sem que os afetados sejam pecuniariamente indenizados. Tampouco haverá a restauração do meio ambiente afetado.

A complexidade das atividades envolvidas no ciclo nuclear brasileiro se reflete na morosidade da resolução destas questões perante o Judiciário. Não é possível cogitar que os acidentes registrados decorram de fatalidades e coincidências alheias ao processo produtivo de atuação da URA-INB.

O descaso demonstrado na sua atuação ao longo das últimas décadas não é, sequer, rechaçado pelas vultosas multas aplicadas pelo IBAMA. Contrariando a exegese de inúmeros princípios administrativos ambientais, o ciclo nuclear brasileiro tripudia, entre outros, do Princípio do Poluidor-Pagador. Transforma violações de direitos humanos em valores sem correspondência adequada.

A lógica da indiferença, que ignora o meio ambiente e as pessoas que dele dependem, é o triste prenúncio do que se pode esperar da retomada das obras de Angra 3. Ao que tudo indica, o município de Caetité/BA seguirá a missão de transcender gerações em litígios pela efetivação do direito humano ao meio ambiente e tudo que lhe é correlato.

\section{REFERÊNCIAS BIBLIOGRÁFICAS}

BONAVIDES, Paulo. Curso de Direito Constitucional. São Paulo: Malheiros, 4ªed., 1993.

COMPARATO, Fábio Konder. A Afirmação Histórica dos Direitos Humanos. São Paulo: Saraiva, 6 ${ }^{\mathrm{a}}$ ed., 2008.

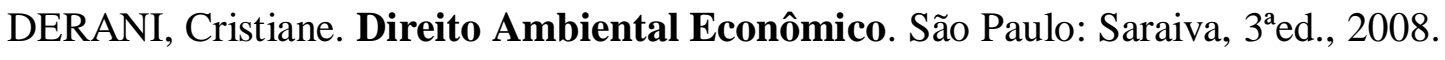

DI PIETRO, Maria Sylvia Zanella; MARTINS JUNIOR, Wallace Paiva. Tratado de Direito Administrativo. São Paulo: Revista dos Tribunais, vol. I, 2014.

FIGUEIREDO, Guilherme José Purvin de. Curso de Direito Ambiental. São Paulo: Revista dos Tribunais, $6^{\mathbf{a}}$ ed, 2013.

FREITAS, Juarez. Direito fundamental à boa administração pública. São Paulo: Malheiros, $3^{\mathrm{a}}$ ed, 2014. 
FREITAS, Vladimir Passos de. Direito Administrativo e Meio Ambiente. Curitiba: Juruá, $3^{\mathrm{a}} \mathrm{ed}, 2001$.

GRANZIERA, Maria Luiza Machado. Direito Ambiental. São Paulo: Atlas, $3^{\text {a }}$ ed., 2014.

GREENPEACE, Relatório Ciclo do Perigo: impactos da produção de combustível nuclear no Brasil, Greenpeace, 2008. Disponível em: <http://www.greenpeace.org/brasil/Global/brasil/report/2008/10/ciclo-do-perigo.pdf>. Acesso em: 14.05.2021.

LAZZARINI, Álvaro. Sanções administrativas ambientais. Revista de Informação Legislativa n. 134, Brasília, ano 34, abr./jun. 1997.

MACHADO, Paulo Affonso Leme. Direito Ambiental Brasileiro. São Paulo: Malheiros, $18^{a}$ ed., 2010.

MARTINS JUNIOR, Wallace Paiva. Princípios jurídicos de Direito Administrativo, Ambiental e Urbanístico e o princípio de precaução. In: Interesse Público - IP. Belo Horizonte, ano 16, n. 88, nov./dez. 2014.

e participação popular. São Paulo: Saraiva, $2^{a}$ ed., 2010.

MILARÉ, Édis. Direito do Ambiente. São Paulo: Revista dos Tribunais, $4^{\mathrm{a} e d ., ~} 2005$.

MUKAI, Toshio. Atuação administrativa e legislativa dos poderes públicos em matéria ambiental. Revista de Direito Administrativo n. 229, Rio de Janeiro, jul./set. 2002.

. Direito Ambiental Sistematizado. Rio de Janeiro: Forense, 10ª ed., 2016.

PIOVESAN, Flávia. Direitos Humanos e Justiça Internacional. São Paulo: Saraiva, 2019.

PLATAFORMA DHESCA, Relatório da Missão Caetité: violações de direitos humanos no ciclo nuclear, Plataforma Dhesca, 2011. Disponível em: <http://www.dhescbrasil.org.br/attachments/499_Dhesca\%20Brasil\%20-

$\% 20$ Missao\%20Caetite\%20-\%20Meio\%20Ambiente\%20-\%202011.pdf>. Acesso em 14.05.2021.

PIOVESAN, Flávia. Direitos Humanos e Justiça Internacional. São Paulo: Saraiva, $1^{\text {a }}$ ed., 2007.

SARLET, Ingo Wolfgang; Fensterseifer, Tiago. Direito Constitucional Ambiental. São Paulo: Revista dos Tribunais, $4^{\mathrm{a}} \mathrm{ed}, 2014$.

SILVA, José Afonso da. Direito Ambiental Constitucional. São Paulo: Malheiros, $8^{\mathrm{a} e d .}$, 2010.

SUNDFELD, Carlos Ari. Direito Administrativo Ordenador. São Paulo: Malheiros, 1997. 